\title{
AN EXPERIMENTAL STUDY OF THE MECHANISM OF HALLUCINATIONS'.
}

\section{By MORTON PRINCE.}

I Assume that the members of this Association are familiar with the traditional theories of the mechanism of hallucinations. I shall, therefore, not refer to them beyond remarking that they may be all classed under one or the other of two groups, viz. the anatomico-physiological theories and the psychological theories; and that all are inadequate and unsatisfactory. It remains therefore to attack the problem anew and, if possible, by experimental methods. We have open to us several methods of attack:

1. By inducing artificially hallucinations, particularly visions depicting known antecedent experiences. A study of their content permits of inferences regarding an underlying process related to the antecedent experiences.

2. Hypnotic methods by which through introspection memories of subconscious processes correlated with the hallucination are obtained.

3. Subconscious, or so-called automatic, script recording subconscious processes during a correlated hallucination.

4. A combination of all three methods.

\section{Artificial Hallucinations.}

I have made studies of a large number of artificial hallucinations in the course of many years experimentation and some twenty years ago published one such study ${ }^{2}$. They are commonly called 'crystal visions,' because the usual technique is to direct the attention by the use of a crystal into which the subject gazes (crystal gazing). A crystal of course is not essential. Merely fixing the attention with expectation of the development of the phenomenon is sufficient with susceptible subjects. An examination of the content of visualizations thus produced shows that they are identical in structure and action with many of the hallucinations of the insane as well as with the spontaneous hallucinations of the sane (Joan of Arc, Fra Angelico, Catherine of Sienna, Margaret Mary of the Sacred Heart, Arch-Duke Charles of Austria, et alii). They are

1 Presented at the eleventh annual meeting of the American Psychopathological Association, Atlantic City, 11 June, 1921.

" An Experimental Study of Visions," Brain, Lxxxiv, Winter Number, 1898.

J. of Psych. (Med. Sect.) $\pi$ 
essentially and psychologically hallucinations artificially induced. (Parenthetically I may remark that it is an extraordinary thing that psychiatrists and psychologists have neglected them as objects of study, as plainly we have here phenomena that can be subjected to experimentation and are capable of giving an insight into the mechanisms of the mind and, as we shall see, into the relation of subconscious processes to conscious processes. One would expect that psychiatrists seeking to determine the mechanism of hallucinations of the insane would begin with artificial hallucinations and that psychologists interested in the problems of imagery would do the same.)

An examination of the content of the hallucinations thus induced reveals that they may be: (a) Visual memories, i.e. reproductions of past visual experiences; $(b)$ visualized memories of past experiences that were not visual (e.g. of knowledge gained in other ways); (c) pure fabrications showing constructive imagination which may represent past thoughts (repressed or not), wishes, forebodings, etc., or attempts to solve problems and doubts, answer questions, etc. Further, when the visualizations are of persons the thoughts of the vision-personality (i.e. those underlying the hallucinations) may emerge into consciousness; and I may mention in passing that the affect pertaining to these thoughts or to elements in the hallucination often wells up into consciousness. (This is a phenomenon of importance bearing on the problem of moods or affectivity.)

More important for our present study, the behaviour of these hallucinations shows that an active process is going on that is not in awareness (i.e. is subconscious), but is inducing the visualization (e.g. when the hallucination has the action of a cinema picture, or represents in visual imagery past thoughts, and is not simply a reproduction or memory of a past visual experience). If we can find out what sort of a process it is, identify it, and discover its relation to the hallucination we shall advance a step towards solving the problem of hallucinations in the insane.

\section{Hypnotic Methods (Coconscious Images).}

There is another class of phenomena which I have called coconscious images. The finding of these came from hypnotic methods, i.e. introspection in hypnosis. They are as extraordinary as they are interesting, but I do not expect you to believe them until you have confirmed their reality by your own observations. My own findings have, however, 
been confirmed by Dr G. A. Waterman in a case of his own ${ }^{1}$. I have found them, according to the evidence of the subjects, in four cases including that of Dr Waterman, who gave me an opportunity to examine his case.

Coconscious visual images may be defined as psychical images of which the individual is not aware and therefore which are subconscious. They occur as:

1. Phenomena of suggested post-hypnotic acts.

2. After phenomena of dreams.

3. After phenomena of repressed thoughts.

4. Phenomena of moods (depressed and exalted states).

5. Phenomena of perseveration of previous emotional complexes (mental systems).

6. Phenomena in the mechanism of hallucinations.

Because of the behaviour of the phenomena in the last class they belong to this study. As phenomena of suggested post-hypnotic acts they permit of experimental induction and study. I have found that each step in such an act (in the cases studied) is preceded or accompanied by a subconscious image or picture corresponding to one of the elements of the act performed or to be performed. Such images occurring with repressed thoughts not in awareness are interesting from a psychological and psychopathological point of view. Sometimes these subconscious pictures are accompanied by an affect which alone emerges into consciousness, as with artificial hallucinations, and apparently determines the conscious mood ${ }^{2}$.

Now the point I am coming to is this: occasionally I have found that one or more images emerge into consciousness and become a hallucination.

This observation led me to postulate a theory of visual hallucinations, namely, that in certain instances at least they were the emergence into awareness of imagery belonging to subconscious thought-the same sort of imagery that occurs in conscious thought.

Auditory hallucinations, similarly, are the emergence of subconscious verbal 'images,' i.e. sounds of words used in subconscious inarticulate thought or internal speech.

1 For a study of these phenomena see article by the writor, "Coconscious Images," Journal Abnormal Psychology, XII, No. 5, Docember 1917. (A report of Dr Waterman's observation is included in this article.) See also The Unconscious: Index, "Coconscious Images."

2 I havo discussed this important phenomenon in The Unconscious, chaps. xII, xIII, xvI1; seo also The Dissociation of a Personality for numerous observations. 


\section{Subconscious Script.}

It remained, however, to prove this by a method not dependent upon hypnotic introspection and memory but by one that would reveal the subconscious thought and synchronously the corresponding hallucinatory images after emergence into consciousness; and the correlation of the two. For this purpose the following procedure was devised: $(a)$ to induce experimentally subconscious processes; $(b)$ to 'tap' the subconscious process while in progress and obtain physical records of it; (c) if any hallucinations occurred synchronously to obtain a detailed description of the same; $(d)$ to correlate by comparison if possible the imagery of the hallucination with the ideas expressed in the written record of the subconscious process; and $(e)$ to obtain immediate evidence by subconscious introspection of the relation, if any, between the elements of the subconscious process and the imagery of the hallucination and the mechanism of the same.

The technique of 'tapping' the subconscious process suited to the experiments and obtaining physical records of the same is subconscious writing, commonly called 'automatic writing.' (Here I may again venture a parenthetic remark: it is strange that psychologists and those engaged in psycho-pathological work have so utterly neglected the study of subconscious writing, both as a phenomenon and a mode of investigating the nature and potentialities of processes outside of awareness, and, I may add, of the dynamic structure and mechanism of the mind. The mechanism of this kind of writing still needs to be worked out as well as the relation of the process to the personal consciousness'.

To carry out the proposed plan of investigation it was necessary to have a subject who both experiences hallucinations and can produce automatic (subconscious) script without awareness of what the hand is writing. (The latter is necessary because some automatic writers become aware of the content of the script as it is being written although it is subconsciously written in that they are not aware of what will be produced and do not voluntarily produce it.) I fortunately have a subject who answers these two conditions and who has been under my observation for about a year. She came to me as a patient for other reasons. I have therefore an intimate knowledge of her character and personality and can vouch for the bona fide nature of the phenomena themselves. She comes of a good, and at one time wealthy, American family and as

1 This important phenomenon has been left to those interested in Psychical Research and spiritualism, who are concerned solely with the content of the writing and not with its psychology. 
a young girl she was, I judge, rather luxuriously brought up: she possesses considerable artistic talent with pencil and brush and has an ambition to develop her voice for dramatic purposes. This is the ambition of her life. These facts are pertinent to an understanding of the content of the script and the hallucinations obtained. She produces automatic script with remarkable facility and has written what would make several volumes in this way, including two or three of fiction and a good deal of verse.

Now on several occasions she had casually remarked that often while she was automatically writing she had experienced visualizations and other hallucinatory phenomena which afterwards she discovered corresponded to the content of the script. Being interested in other aspects of the case I had merely made a note of the fact at the time without further attention. Later, when I took up the question of hallucinations for study it occurred to me at once that here I had just the subject I wanted at hand. The conditions of the experiments were arranged as follows:

The head of the subject was covered with an opaque cloth to prevent her seeing the script as it was being written automatically by her hand. A pencil was then put into her hand which rested conveniently on a sheet of paper placed on a writing tablet by her side. She was then told to write automatically regarding some subject which I designated in general terms in each experiment: for instance, a memory of some remembered episode in her life, a memory of such an episode but one forgotten by the subject; a fantasy; a fabrication requiring constructive imagination, etc. The object of diversifying the subjects was to obtain products of different kinds of subconscious work (memory, dream-like fantasy, imagination, etc.). If, during the experiment, while the hand was writing, a hallucination developed, the subject was directed to indicate the fact the moment she saw it by exclaiming 'picture.' Thereupon I made a mark on the script at the point where the picture appeared. Likewise the moment the hallucination disappeared the subject exclaimed, as directed, 'gone,' and the point was similarly marked on the script. Thus those words of the script which were written during the occurrence of any given hallucination could be identified and could be compared with the latter and any correlation of the written ideas and the hallucinatory images noted.

In some cases as soon as the hallucination appeared the subject was required to describe orally the 'picture' in detail. This description was taken down by me verbatim. Two things, be it noted, were thus being 
done by the subject at one and the same time; namely, writing with the hand one thing, of which she was not consciously aware, and describing orally and consciously another thing-two entirely different processes, one subconscious and the other conscious.

In other experiments the subject was not required to describe the details of the hallucination until after it had disappeared, but only to indicate its beginning and ending and its general character, such as of a person, or place, or thing - " a ship on the ocean"; "a street in a city," etc. As soon as it disappeared the writing was interrupted and the subject was required, while the memory was fresh, to describe the details of the hallucination. This having been done the writing was resumed and this procedure continued until the script was finished, when, as it happened, the hallucination always ceased. This method was found to be the most practical for reasons I will not go into because it would involve a lengthy. discussion of the principles underlying the phenomena of subconscious writing.

After the observation was complete, the script and the hallucination as recorded were compared and for this purpose arranged in parallel columns. Thus any correlations between the imagery of a hallucination and the synchronously written script could easily be noted.

Finally, after each observation the method of subconscious introspection was used to elicit such evidence as might be obtainable as to what occurred subconsciously during the writing of the script and the hallucination, i.e. what was the character of the subconscious process that produced the script; what (if psychological) was its content; what, if any, psychical elements (such as images) of which the subject was not consciously aware were present; and what, if any, light could be thrown by subconscious introspection upon the relation of the subconscious process to the hallucination? Very positive introspective testimony as to the source of the imagery of the hallucinations and the relation of those images to the subconscious process was thus elicited. Its credibility must be judged according to the value assigned to the method. A summary of this evidence will be reported in its proper place, after the various scripts and their accompanying hallucinations have been given.

Before giving the results of the experiments the following facts in the psychological history of the case will enable you to understand the rather fantastic content of the text of some of the script and imagery. The subject had at a previous time exhibited the phenomenon of double personality and for this reason had been sent to me for study and readjustment. This phase of the case had been recovered from at the 
time when the experiments were undertaken. During this previous phase one of the personalities called 'Juliana' had imagined as a fantasy that she was the reincarnated soul of a Spanish peasant girl of the thirteenth century and, after the fashion of secondary coconscious personalities of spiritualistic mediums (as in Flournoy's case of 'Hélène Smith'), imagined that she remembered her previous life as such a peasant. A most elaborate and extravagant romance of the thirteenth century had thus been fabricated beginning with her early girlhood as a rustic peasant and ending in her death in old age after many adventures as a street singer and finally as a great artist with a wonderful voice, having sung and danced before the King's Court and great audiences, one of which was gathered in the Coliseum in Rome. The genesis of this fantasy could be traced, I think, to the day dreams of the subject as a young girl and later to dreams under the influence of morphine during a serious illness. But as elements in it could be recognized, as motivating factors, her life's aspirations. As Juliana, a secondary coconscious personality and also an alternating personality (to whom 'Susie' used to change from time to time), she would play the part seriously and honestly of a Spanish girl, spoke broken English with a foreign accent, and also a supposititious Spanish dialect of the thirteenth century which, of course, was only a neologism (nicknamed by me the 'lingo'), and acted the part well.

After reintegration the subject consciously and coconsciously remembered in complete detail the so-called 'Spanish fantasy,' and, according to well known principles, the conserved subconscious systems could be 'tapped' and made to a degree, as artifacts, to manifest themselves as more or less temporarily dissociated autonomous systems.

In the cure, that is the reintegration of the two personalities into one normal one, the belief in all this fantasy, previously strongly held by Juliana and accepted by the other personality, was, of course, destroyed.

It need only be added that at the time when these observations were undertaken the subject, owing to reversals in the family fortunes, was obliged to earn her living and was employed in a large department store in which she rendered excellent service as a saleswoman. She regarded this, however, as only temporary, hoping later to achieve the object of her life-long ambition, to cultivate her voice for a career upon the stage.

I will now give the results of the experiments, not in the order in which they were made, but classified according to the type of content of the script and hallucination. 


\section{A. Subconscious (Automatic) Writing Accompanied By Visual Hallucinations.}

Observation $I$. In this observation both the script and the hallucination record a memory of an episode which occurred two or three years ago when the subject, as I have explained, exhibited the secondary personality of 'Juliana.' The subject now consciously remembers the episode here described at the University. (Susie is the name of the normal personality; 'Dr Jones' is assistant professor of philosophy.) To conceal the identity of the subject fictitious names, including that of the University, have been substituted throughout.

\section{A Memory of a Previous Episode in the Subject's Life.}

The subject was directed to write automatically an account of some episode in her life making the selection herself subconsciously. (Of course neither I nor the subject had any suspicion of what it would be.)

SCRIPT: "I was at Harvard [University one day with Dr Jones when I changed into Juliana for Dean Smith and he] was pleased with me. I went [through all sorts of gestures as Juliana and] I spoke 'lingo' for 3

[the men and they seemed very much interested and the Dean never] took his eyes off Juliang."

While the hand was writing this script automatically without awareness on the part of the subject, the first 'picture' (hallucination) appeared when the word "university" was written and continued until the word "he" was written, when it vanished. This is indicated in the text by the words in italics enclosed in brackets and designated by the number 1 . Similarly the second picture appeared synchronously with the word "through," and ended after the writing of the words "Juliana and"; the third picture appeared with "the men" and ended after "never."

The hallucination (as described and taken down verbatim by me) and the script were now compared to see $(a)$ if and to what extent its images were synchronized with the 'ideas' contained in the script, and (b) if the images corresponded to and represented these ideas thus synchronously expressed in the writing after the manner of conscious imagery.

For clarity the script and the hallucination are arranged below in 
parallel columns, each 'picture' being set off against those portions of the script that were written during its occurrence.

( $I$ trust this explanation of the phenomena obtained in this experiment and of the form in which they are now presented will be sufficient for a comprehension of all the succeeding observations that follow, as the same plan was adhered to in each.)

SCRIPT

1. I was at Harvard [ Universily one day with Dr Jones when I changed into Juliana for Dean Smith and he] was pleased with me.

2. I went [through all sorts of gestures as Juliana and]

3. I spoke 'lingo' for [the men and they seemed very much in. terested and the Dean never] took his eyes off of Juliana.

\section{Hallugination}

I see Harvard Univorsity. The steps going up and the brown stones and the whole front of the building I seo myself as Susie going up the steps and into the building and I go down the hall to Dr 'Jones' office. Dr Jones is there and Dean Smith. They rise and shake hands and then sit down. I sit down as Susie and I see myself sitting in a chair and I turn into Juliana. I rise again as Juliana and shake hands again. Thoy seem pleased. (The whole vision is like a movie.)

I see myself sitting in Dr Joncs' office as Juliana and $I$ am going through all sorts of funny gestures like a foreigner. They laugh. (I cannot hear them.)

I see myself as Juliana and I am talking the 'lingo'-- (I can heur the words-but cannot tell what they are). I cun hear Dr Jones' voice as if he is saying this is "an interesting phase" (the exact words).

If you will take the pains to examine carefully these results and compare the script with the corresponding hallucinations you will note several things:

1. At the moment of the occurrence of the subconscious writing of the words "Harvard University," and the words describing each succeeding step of the original episode, a visualization, or hallucination, or image-call it what you will-corresponding to and representing the ideas or thoughts expressed by the subconsciously written words developed in consciousness. I am particular to express it this way because it must not be forgotten that all we have are certain physical marks (writing) on paper (of which the subject, let it also be not forgotten, was unaware) and a described hallucination. But if we accept the doctrine that automatic script is written by actual coconscious thoughts not in awareness rather than by purely physiological processes ${ }^{1}$ we may with equal accuracy express the facts and avoid pedanticism by the formula: at the moment of the occurrence of a subconscious memory or

1 I am not certain that it makes any difference in our conclusions whether tho writing is done by physical or psychical processes. The point is the correlation of imagery with a subconscious process that is equivalent to a thought and corresponds to the image or images. 
thought (not in awareness) of Harvard University and of each succeeding step of the original episode a visualization corresponding to and representing that thought-memory appears in conscious awareness.

2. These visualizations resemble and perhaps we may say simulate or are identical with the ordinary visualizations of conscious thought although they may be richer ${ }^{1}$ in detail and more vivid.

She subconsciously thinks of being at Harvard University, as had happened on a certain occasion, and almost at once she experiences not only images representing a building at Harvard, but also images of herself in movement, walking up the steps, into the building and down the corridor to 'Dr Jones" room, as she did in the original episode. And so on with the remainder of the episode described in the script.

3. The visualization (hallucination) was much richer in detail than the description of the episode given in the script. I shall come back to this fact and discuss it more fully later. I will merely point out now that this is also true of the imagery of conscious thought and particularly of written thought. When I write "I took such a train for New York," with the thought of having taken the train I may have an elaborate imagery of the Boston station of the N.Y. and N.H.R.R. crowded with bustling people, of entering the gate with other passengers, of the long train of cars standing by the platform of the station, etc. More or less of all this I may have and do as I write it, according as my mind dwells on the incident and gives time for the thoughts and images to develop. And yet I only precisely think and still more only write, "I took a train." A good visualizer has very rich imagery for very simply expressed thoughts.

4. A moment elapses after the script begins to describe the incident before the correlated image develops. For instance, the image of the University building does not develop until after the four words "I was at Harvard," were written. This slight delay in the development of the hallucination is of considerable significance and I will come back to it later after the results of the other experiments are given. We shall find better examples of it and also of the correlation of script and imagery in the more elaborate scripts and hallucinations. In fact I begin with this simple type of script and imagery that the main principle involved in all the experiments may be first clearly understood.

5. Finally I would point out that the three 'pictures' in this experi-

1 Although this qualification is true by comparison with the imagery of the average run of individuals it may be doubted if it is true by comparison with the imagery of some persons who are extraordinarily vivid and elaborate visualizers. 
ment can be recognized easily as continuations of the same theme. But although this was always the case, we shall find that with most of the other hallucinations there is no obvious continuity to the pictures. The scenes shift as in a dream without apparent relation to one another. The significant fact is that the continuity will be found in the subconsciously written script without which the varying hallucinations would not seem to be related to one another and could not be understood or interpreted as manifestations of one and the same theme.

All these points should be borne in mind when studying the phenomena of the other experiments.

Observation II. (This was the first and a preliminary experiment to determine the best technique.) The subject was directed to write subconsciously a fabricated story constructed out of her former so-called 'Spanish dreams'-those of the Juliana system which had as a second personality conceived itself to be the reincarnated soul of a Spanish peasant girl and had created an elaborate fantasy of a previous life in Spain in the thirteenth century. The scenes and personages incorporated in the script had been often previously imagined. The images of the hallucination were therefore reproductions of former imagery. The image of Juliana, for instance, was reproduced exactly as it had always been visualized in the Spanish fantasies. (See Observation IV for a drawing of Juliana and the dancing scene.) The visual images were accompanied by a number of auditory 'images' and also by somatic sensations and feelings. These latter were the same as those which had always been associated with the conception of herself as a Spanish girl. Hence the script begins "I feel I am Spanish through and through."

In this preliminary experiment the scenes of the hallucination were described in detail from memory after the completion of the script. In thus recalling the scenes the imagery was revived again and described from the reproduction. The images, both as they occurred in the hallucination and as revived, were said to be very vivid, more vivid than when experienced in the original fantasies, and were likened to the pictures of the 'movies.'

\section{The Spanish Fantasy.}

ScRIPT: "I feel I am [Spanish] through and through. [As I paddled barefooted through brooks] and carried [jugs of water upon a yoke and danced barefooted before the king of Spain and his Court-Cortes]. Also when 
[I walked to early mass at the village church or mission at a village called in my time Medesa]. And of [Father Brazado, the priest who discovered my voice]. [I have a voice. I shall always believe I am a soul."]

ScrIPT

1. I feel I am Spanish through and through.

2. As I paddled barefooted through brooks

3. and carried jugs of uater upon a yoke

4. and danced barefooted before the King of Spain and his Court-Cortes.

5. Also when $I$ walk to early mass at the village church or mission

6. at a village called in my time Medesa.

7. And of Father Brazado, the priest who discovered my voice.

\section{Halluotation}

Indicated by certain strong feelings and somatic sensations which emerged in association with the image of Juliana, a revival of a fantasy of herself in a previous existence as a Spanish peasant of the thirteenth century.

A brook. Juliana is walking through it barefooted with her skirt doubled up in front but falling behind, showing her petticoat of a very coarse cloth, such as a peasant might wear. (Here the subject remarks, it is "a very pretty picture.")

\section{[Shift] ${ }^{1}$}

Juliana has water jugs on a yoke on her neck carrying them from $a$ fountain in the village. [It is a village not a city because she sees earth around the fountain.] "I feel as if the image that is Juliana is a part of me.")

$$
\text { [Shift] }
$$

Juliana dressed in dancing costume - marble floorsdraperies-flickering lights. She is dancing as Juliana has danced in real life. The scene is such as if it is a King's Court-a lot of people there-men as well as the women are dressed in long robes. That is the men do not wear knee breeches, etc. (The costumes are such as are represented in pictures of medieval times.)

[Shift]

A road. At the end of the road a little church. A sort of white stucco mission church. Juliana's back is towards me. She is walking down the road barefooted going to the church. The whole is as plain as a motion picture. I can see the grain waving in the adjoining fields. ( $I$ have the feeling as if she is lazy and does not want to go to church.)

\section{[Shift]}

A sort of square. I can see her uncle Salvator. There is a tent propped up over a lot of vegetables exposed in the market place. A lot of foreign looking women are walking about. There is a crowd.

\section{[Shift]}

A priest-(a man just as vivid as I can see you) medium height - fat-big fat stomach, dressed in a long black robe. Around his waist is tied a cord, a funny twisted cord like nothing I have seen. (Here she imitates with her fingers the twisting of the cord.) He has a

1 Note the shifting of the scene after each hallucination without apparent continuity of action which is to be found only in the theme of the script, that is, in the subconscious process. The exact points in the seript where two of the hallucinatory scenes ended are not quite cloar in my record, so that the time interval between them and the next ones is not apparent. 
grayish board and is walking down a roadway. Fields on each side. Juliana, with thick black hair flying behind as if the air is blowing it, short skirts, bare legs, is raking in the ficlds. I can hear her singing in the Spanish 'lingo.'

8. I have a voice.

[Shift]

Juliana vividly singing in a sort of arena like the Coliseum in Rome. There is a big crowd of heads in the Coliseum. I can hear a voice singing in the 'lingo.'

On examination of the details of the script and the synchronously occurring hallucinatory imagery, we see that the latter is composed of just such images as the thought contained in the script would normally incorporate. The subconscious writes "As I paddled barefooted through brooks," and at that moment the subject consciously sees an hallucinatory Juliana walking barefooted through a brook, her clothes made of coarse cloth tucked up in front, etc. The picture of Juliana was identical with previously imagined pictures of herself as that personality.

The subconscious writes "and carry jugs of water upon a yoke," and thereupon the scene shifts and the subject sees an hallucination of herself as Juliana carrying water jugs on a yoke on her neck from a fountain in a village.

The subconscious writes "and danced barefooted before the King of Spain and his Court" (a scene from a former fantasy) and straightway the picture shifts again and the subject sees an hallucination of just such a scene at an imaginary Spanish Court. (This dancing scene had been previously constructed in subconscious fantasy and several times was reproduced in the course of this and other observations. (See Observation IV.)

The subconscious writes, "also when I walk to early mass at the village church or mission," and the scene of the hallucination shifts, a little church appears at the end of the road and she sees herself as Juliana walking down the road, etc. The imagery, as in all the other scenes, perfectly corresponds to the thought expressed in the script and is precisely such as such a thought would incorporate bearing in mind the Spanish setting and peasant personality. And so on with the succeeding three scenes. In her previous dissociated personality she had frequently constructed these same scenes with the same imagery which appeared in corresponding hallucinations. The scene in the Coliseum, for instance, she had previously constructed and had woven it into her fantasy of her previous thirteenth century existence. (Before these experiments were undertaken I had already heard this scene described in vivid detail.) 
The richness of the imagery in each scene should be noted. When, for instance, the script speaks of the priest "Father Brazado" the corresponding image is not simply of a figure or face, or even a priest, but of a priest portrayed as a personality with particular physical characteristics. It is a piece of character drawing done much as would be done in a play or novel. This character is also given a setting rich in local colour comprising a roadway and ficlds in which Juliana appears as a peasant girl at work with her rake. Now all this is derived from a previous fantasy which had been constructed as a dream-like work of fiction. The imagery, in other words, includes and is largely constructed out of images belonging to associated ideas as happens in normal conscious ideation. One thinks of a certain person, and images of that person in a particular setting of previous experience arise. Similarly when the script states, "I have a voice," the image is of a particular experience when in fantasy she sang in the Coliseum to a crowded audience. This experience is a pseudo-memory which arises subconsciously.

This richness in detail and extensiveness of the imagery of a hallucination, transcending the verbal limits of the script, is noticeable in all the observations and will be discussed later with the evidence from subconscious introspection. As already stated this evidence was elicited after each observation as part of the technique, but it will be more advantageous to consider all this evidence together.

Observation III. For the following experiment the subject was instructed a day or two in advance to be prepared to write automatically at the next visit a fabrication in the form of a story or anything else of an imaginative character on any subject she chose subconsciously to select, but something distinct from the Spanish dreams of Juliana; that is, something that would be original and not a reproduction of former fabrications. Thus a chance for subconscious incubation was given. The result turned out to be a poetical (?) glorification of the talents which she has always felt consciously and particularly subconsciously, she possessed, but to which she had been unable to give expression owing to the circumstances of her life. The hallucinations were allegorical in form. It was interesting to watch the hand erasing and altering the phraseology as in conscious composing. There was evident difficulty owing to not being able to see the writing and therefore having to keep the written words in mind. 


\title{
III. A Poetical Glorification of Her Own Talents.
}

\author{
SCRIPT: "Open wide thy treasure chest ladened with gifts so rare. \\ And sing thy song of rapture of beauteous skies so fair. \\ 2 \\ Thy tones will fall as gems that fell from founts of gold \\ And the echo of thy song shall die away like strains from lutes \\ of gold. \\ Pandora's box is poor compared with all $I$ hold \\ Within, and appears as a box of snuff to the one \\ Who knows, who sees, and who can tell \\ Glorious [picture grows larger] splendor of skies of roseate hues, \\ And the heavenly grandeur of azure."
}

\section{Sortp'T}

1. Open wide thy treasuro chest ladened with gifts so rare.

And sing thy song of rapture of beauteous skies so fair.

2. Thy tonos will fall as gems that fell from founts of gold

And the echo of thy song shall die away like strains from lutes of gold.

\section{Haliucination}

$A$ big chest rises up in my mind- it is hetwily carved - a gorgeous thing. At first it is closed and then it slowly opens. As it opens $I$ see that there are in it beautiful strings of pearls and red and whito roses. I see vials like cut glass fagons, and instead of seeing the liquid perfume in the flagons there comes out a sort of vaporous cloud that is perfumed, because I can actually smell it. And on the edges of this chest are beautiful birds, like pure white doves. Thoy are alive and it seems as if $I$ hear them cooing us in the spring time. I actually hear them coo. Then finally, a foggy vapour seems to covor the whole, to swallow it up, and it disappoars. (It all socms to symbolize boautiful things.)

I seo a founlain. It is beautiful. It is of green malachite. The base of this beautiful fountain is formed of funny littlo croatures that seem to be half animal and half human. They have the faces of goats, with horns and tails and hoofs. They sem like human beings and yot they are goats. (It seems as if I havo seen such things before-such as might be in Midsummer Night's Dream.) There ure four of these figures holding up a big bowl, that of the fountain, which is about five foot tall. It seoms to bo located on the edge of a wood. In the background I can see light coming through the foliage. Flowing out of this fountuin the beautiful crystal water falls over the edgo into a busin at tho bass. And beautiful gems-rubies, emeralds, etc. fall out over the edye along with the water, as if thoy were bubbling out of the bowl, and falling into the basin they disappear. Around the basin at the base were lutes, and harpsgolden instruments. I can hear beautiful soft music in. wardly. (I have often heard such inward musio bofore. I have often got out of bed to dance to this inner music.) The music seems to come from the instruments although nobody plays upon them. It is very low, dim, soft music. (The vision seems to symbolize the natural gifts I have within me.) 
3. Pandora's box is poor compared with all $I$ hold

Within, and appears as a box of snuff to the one

Who knows, who sees, and who can tell

Glorious [picture grows largor] splendour of skies of roseate hues,

And the heavenly grandeur of azure.
First I see a picture of a woman angel. She is holding a jewel box in her hand and butterflies are flying out of it. It seems to diminish in size until it gets real tiny. While she is holding it and as it becomes small, rays of light shoot up over the whole and shut out the angel.

These rays turn into a beautiful sky. ['This was when the vision grow larger, as indicated in the script.] The sky is blue and pink. (It is very beautiful.) Then clouds form in the sky and then they break and show the pink colour through.

The correlation of the several elements of the hallucinations with the synchronously written words is strikingly manifest.

The hand writes "Open wide thy treasure chest-ladened with gifts so rare," and in a moment or two she visualizes a treasure chest slowly opening and disclosing gifts of rare value.

The script exhorts her to sing a song of rapture, and at the same time in the allegorical visual and auditory hallucinations she both sees and hears beautiful white doves cooing as in the springtime.

The script compares the tones (or words) of her song to gems falling from a fount of gold, and she straightway visualizes a beautiful fountain from which gems bubble out along with the crystal clear water.

The script compares her song (i.e. musical voice on which is centred her ambition) to the strains of golden lutes, whereupon synchronously she visualizes golden lutes and other golden instruments lying at the base of the fountain, and she hears "beautiful soft music inwardly" coming, as it seemed, from the instruments.

The script compares the gifts she holds within herself to those Pandora possessed in her box, to the disparagement of poor Pandora (of whom and the contents of her box by the way, her knowledge is very inaccurate ${ }^{1}$ ), and correspondingly she sees a vision of a "woman angel" (the facsimile of a picture in her possession which she, as it later transpired, imagined was that of Pandora) holding a jewel box in her hand.

The script emphasizes her own marvellous knowledge and gift to describe in song the splendour of roseate skies and the grandeur of the heavenly azure, in comparison with the poor little talents belonging to Pandora and contained in her box, and straightway in the vision only butterflies come out of the box which diminishes to a tiny size, and Pandora and the box are eclipsed by splendid rays of light which turn into a beautiful sky of pink and blue.

Another point worth noting is the wealth of imagery of the hallucina-

1 As I later determined. 
tions. If this imagery may be interpreted to represent symbolically the meaning of the script it approaches allegory with free use of symbolisms and analogies. For instance: her own personality laden with rare inborn gifts, or talents, is likened to and symbolized by a treasure chest filled with gifts of pearls, roses, cut-glass flagons, etc. As she exhorts herself to display her own gifts so she sees the treasure chest open and display its contents, and, somewhat astray in her knowledge of mythology and the contents of Pandora's box (as I afterwards discovered) she compares the gifts contained within herself to those of Pandora, to the disparagement of that mythological lady. Likewise the rich imagery of the fountain with its gems bubbling out with crystal water. All this reminds us of conscious imagery in composition of poetry, oratory and descriptive writing.

Observation $I V$. In this Observation the script records a subconscious memory of a consciously forgotten episode; that is a dream of which the subject has no remembrance nor of the circumstances excepting that during a severe illness years ago and while under the influence of morphine she had a dream of some sort of Spanish character. This was before the break-up into a double personality and the evolution of 'Juliana.' Indeed it was out of the fantasies of such night and day dreams, as I interpret the case, that the Spanish personality later became constructed. The hallucination is particularly interesting as it represents a dream within a dream, with corresponding shifting scenes of which the continuity is to be found in the subconscious script. The hallucination was described orally while the hand was writing the script.

\section{A Subconscious Memory of a Forgotten Dream.}

\section{1}

Soript: "Once when I was ill in the South I wished I was a strong woman; I wished I was a Spanish girl and this is what I dreamed :- that 2

I was a Spanish maiden of rare beauty and charm, and then I saw her 3 siting on a stump and 1 seemed to see her dreaming. $I^{1}$ sitting on a stump and I seemed to see her dreaming. $I^{1}$ see her in a palace where there is soft music and there seems to be grapes and flowers and beautiful pictures and oil urns of coloured lights."

1 'Tho exact moment of emergence of the last two pictures (3 and 4) by an oversight was not noted on the script. They are here given upproximately. 
Halluoination

\section{SCRIPT}

Once when I was ill in the South I wished I uxis a strong woman; I wished I was a Spanish girl and this is what I dreamed:

\section{[Dream of Susie]}

that I was a Spanish maiden of rare beauty and charm

and then I saw her silting on a stump of a tree and I seemed to see her day-dreaming.

[Dream of Juliana]

$I$ see her in a palace where there is soft music and there seems to be grapes and flowers and beautiful pictures and oil urns of coloured lights.
Described orally while the hand was writing

I see myself in bed. I' $m$ sick. I see a rooma bed in it, a brass bed. I am real weak. I prop myself up on a pillow. I seem to be like I was dreaming-I see myself lying back on the pillow. Now I am asleep.

\section{[Shift]}

1 sco Juliana going into the woods. She is plump with poor clothes-her hair is hanging down her back - she is barefooted. [Commont after the cessation of the hallucination; "She was very pretty."]

[Shift]

Juliana is silling on a $\log$. She seems to be dreaming. As I see her I seem to see her dream.

[Shift]

I see this peasant girl in a beautiful palaceshe has beautiful robes on-there is beautiful statuary in the palace - a lot of gaiety around her -a lot of people as in a court-soft music-I hear it-and a lot of light coloured light from urns and lots of fruit - beautiful marble mosaic floorsthe girl is dancing.

After this experiment the subject again visualized the 'pictures' of Juliana sitting on the stump of a tree and the scene of the palace and drew the following illustrations (Figs. 1 and 2) from the visions which she actually saw as if they were real. The mechanism of this revisualization was found on examination to be very similar to that of the production of a crystal vision. There was, also, as was claimed, a coconscious wish ("a great desire") to have the coconscious images emerge into consciousness so as to be drawn.

The dancing scene at Court had been frequently visualized and was therefore an already organized construction. She had little more than to think intensely of it coconsciously to have it reappear. It was a repetition of scene 4 , obs. II.

The script begins to tell of an illness which the subject suffered a good many years ago when living in the South and after seven words are written an image of herself ill in bed, in the very same brass bedstead and in the very same room in which she had been ill appears in consciousness. (It is a visualized memory for on seeing the vision she recollects the illness, the room and the bedstead.) The whole hallucination is composed of just such images as would accompany the recollection of such an episode as one would experience when one recalls a particularly serious illness that one has suffered in a particular place. She had been 
prostrated at the time, as she well remembers, and the hallucination portrays her as weak in body and the script described her thought as wishing to be strong, to be in fact the strong peasant Spanish girl whom

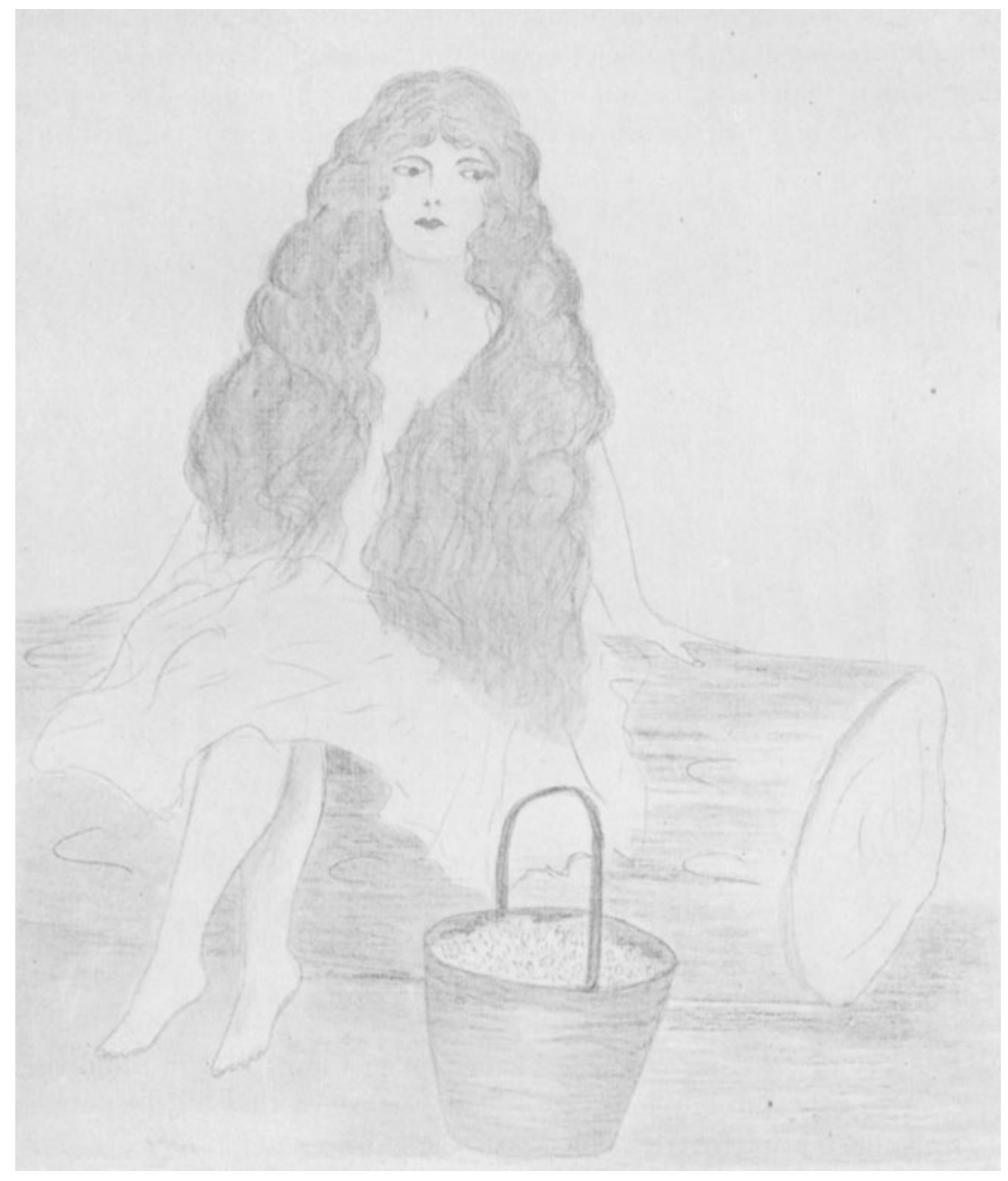

Fig. 1. Juliana drawn by tho subject from a hallucination.

in her day-dreaming she had fabricated as a fantasy; and so she goes to sleep and dreams the fulfilment of this wish.

She dreams (according to the script-whether true or not does not 
matter, for it is only with the content of the subconscious process that is writing that we are concerned) she dreams, so the script goes on, that she is a Spanish maiden and the image of such a maiden of "rare beauty and charm" appears as a hallucination but in a particular setting of the woods. The figure is an image identical with that which she had often fabricated of the Spanish peasant Juliana and just such an image as the maiden of the script would in conscious thought evoke. The setting of the woods is not described in the script but, as has been pointed out,

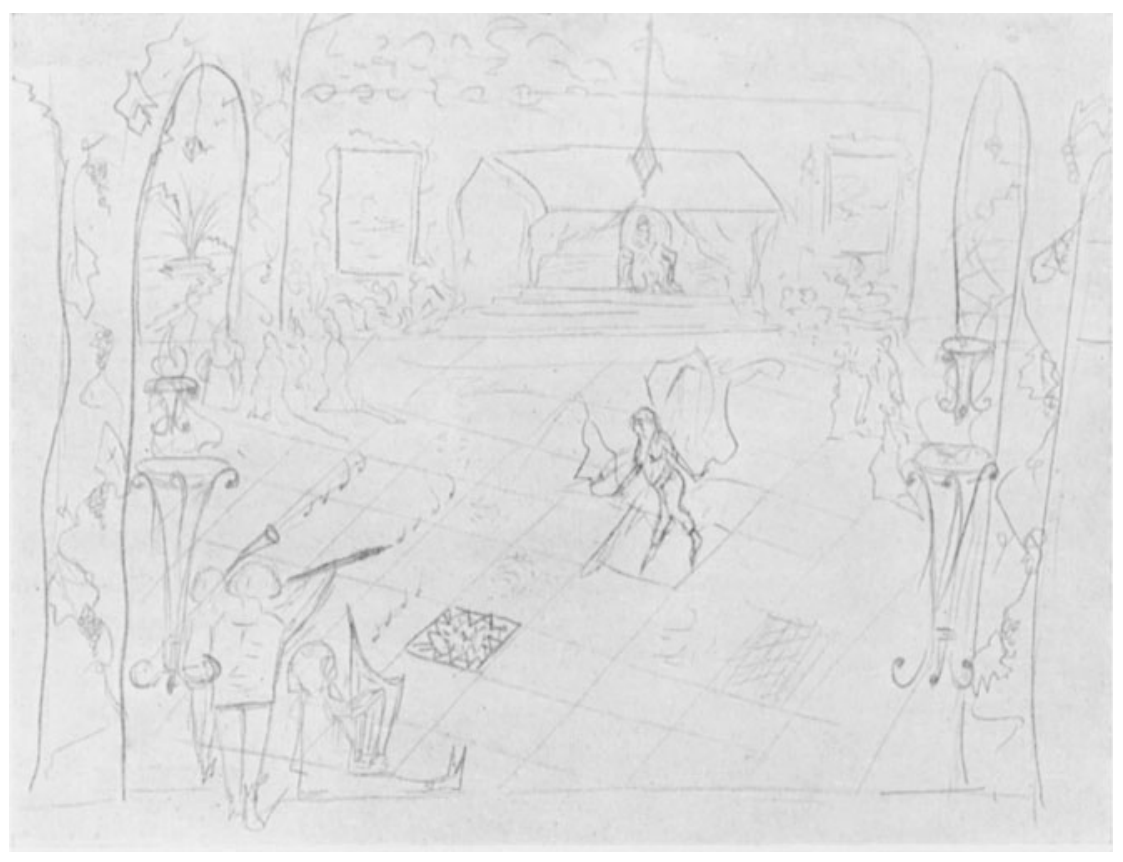

Fig. 2. Juliana dancing beforo the king (drawn as in Fig. 1).

the imagery of a hallucination is always richer than the script and the testimony of the subconscious introspection affirmed that all the details of the hallucinations were elements in the subconscious process as we shall later see. Then, as the subconsciously written script described the maiden sitting on a stump of a tree, day-dreaming, straightway a corresponding image of Juliana emerges as a hallucination. (Let us never for one moment forget in studying these phenomena, that the subject was entirely unaware of the content of the script-of what the hand had written, and therefore whatever images pertained to and 
emerged from the expressed ideas must have pertained to and emerged from a subconscious process, and, if the script was written by a subconscious process, such as the content of that script would require.)

The script declares that (subconsciously) she sees the imagery of the dream and this imagery emerges into consciousness as a hallucination of Juliana dancing before the King and his Court-a long previously organized fantasy.

Thus examined the imagery of the several shifting scenes of this hallucination is preciscly such as the content of the seript would require; if we are justified in defining that content as coconscious ideas, wo may say such imagery as those coconscious ideas would contain.

Observation $V$. The chief interest in the next observation lies in the facts $(a)$ that the script was motivated by anxiety and not by a wish and therefore the hallucination was not a wish fulfilment; and $(b)$ that the emotions linked with the subconscious process (a memory) emerged into consciousness along with the images of the memory. The emotions involved were both anxiety and anger, but it would seem that anxiety was the dominant emotion of the subconscious system producing the script while anger was that which was felt most strongly at least by the subject while seeing the hallucination. Apparently during the original episode, of which the hallucination and script were a memory, both anger and anxiety were elements. For this observation, it should be said, the subject had been directed to write automatically a memory of some episode in her life of an anxious kind. Of course neither the subject nor I had any idea of what would be written.

The occasion referred to in the script and reproduced in the hallucination was one when the subject was in the clinic of the commercial establishment (where she was employed) to get her time card signed for the days she was absent on account of illness. The nurse must pass on such cases.

\section{Memory of an Anxious Episode. \\ Schirt \\ Hallugination}

"Yes, I am concerned if they will sign my time card and she is cold in her attitude towards me."
(Described orally und synchronously while the hand was writing)

I see the nurse sitting down at her desk talk. ing to mo in the clinie down at the store, and $I$ seem to be perplexed about something, I don't know what. She turns hor head and writes something on a card. (She was sort of haughty.) 
[Note: The script further claimed that she felt (subconsciously) while writing really anxious because it meant much to her if the card were not signed and her pay was 'docked.']
[Oral comment by the subject:]

"A feeling of doubt and of being full of fight comes into my mind.... While seeing the hallucination I felt worried as if my word was doubted, as if I were put on a level with other girls who tell a lie whenever they open their mouths....I had that feeling at the time."

Immediately after the observation was finished the following questionnaire was put to the subconscious system. The answers were written automatically without the subject's awareness of their content.

$Q$. "What were you concerned about?"

$A$. "Whether the nurse will put a D.D. [Don't dock] on my card."

$Q$. "Were you anxious?"

A. "Yes."

Q. "Was the conscious mind anxious?"

$A$. "No." [Here in reply to my question the subject said, without knowing what the hand wrote, that she was not consciously anxious at the time of seeing the hallucination but only resentful.]

$Q$. "Were you really anxious?"

$A$. "Yes, and it would mean something if I do not get it signed."

Temporal Relation between Script and Hallucination.

It is obvious that there are two possible interpretations of the relation between the script and the hallucinations in these observations. First, the hallucination may be secondary to and a product of the script producing process; or, second, the hallucination may be primary and the subconscious process may simply describe in the script an independent hallucination. The point is crucial: for if the second interpretation be the correct one the hallucination could well be the product of an independent and unrelated process. In favour of the first interpretation and against the second is the fact to which I have called attention, that the writing of a given script always began before the correlated images appeared in consciousness. A moment or two always elapsed after the idea began to be written before its hallucinatory image developed. This can easily be recognized by noting the point marked in the script of the emergence of the image. If the script simply described a primary and independent hallucination we should expect the latter to have appeared first and the descriptive writing of the imaged idea to follow later. But the reverse was the case.

Then again the script is never technically speaking a description of the hallucination (such as the subject herself gave when she experienced 
it), but rather a theme in which the expressed ideas would normally have just such images as appeared in the corresponding hallucination.

Further evidence confirmative of the first interpretation was obtained by subconscious introspection-the next step in the investigation. The evidence of introspection was to the effect, as we shall see, that the subconseious process was primary and the hallucination secondary; and that the latter was due to the emergence into consciousness of images belonging to and first formed in the subconscious process.

\section{Introspective Evidence from Self-Analysis by the Subconscious Process.}

The next step in this study obviously was, as stated in the beginning, to learn what light, if any, the subconscious process itself could throw upon the relation between the images (hallucination) and the writing consciousness; and for this purpose to obtain a self-analysis based on introspection by the subconscious process that wrote the script. Such an introspection would be similar in every way to the conscious method commonly employed in psychological laboratory investigations. It would make use of retrospective memories of the content of the subconsciousness. Its value as evidence would depend like all introspection on the accuracy and completeness of subconscious introspection.

The technique in the present investigation consisted in presenting a carefully worded questionnaire to be answered by automatic script and followed often by a rigid cross-examination of the replies, care being taken to suggest no leads or theories.

Accordingly after each of the first four observations the subject was submitted to such an examination. The content of the subconscious process, whether or not it contained images and thoughts and, if so, whether or not such images were in any way related to those of the hallucination, or to the subconscious thoughts (if there were any) producing the script, of course could not be known to the personal consciousness, nor were the answers known until after the interrogation was finished. The self-analysis, introspection and replies were, therefore, necessarily subconscious.

\section{(Observation I: Harvard University.)}

The replies of the script following Observation $I^{1}$ (the scene at "Harvard University") are striking in that, without any suggestion of

1 As here arranged the observations are not in the sequence in which they were actually made. This observation was the third following the "Treasuro Chest" (No. 3). 
any theory whatever on my part, or indication of any mechanism by which the hallucination might be formed, the script clearly and explicitly described the origin of the pictures or images in the subconscious process and their later emergence into consciousness as the hallucination. The only possible suggestion was in the question whether or not the pictures were in the subconscious mind 'also' as well as in the personal consciousness, as surely might well be the case, whatever the mechanism. For subconsciously there is awareness for all that which is in the personal attention. The question only related to a possible memory of a possible past experienced fact, not to an opinion or general idea, or other thought. The affirmative answer can scarcely be questioned in view of the fact that subconscious images are not a novel phenomenon, as I have recorded them in at least three other cases; and, secondly, in this case they were repeatedly deseribed to me long before I undertook this investigation, and were then as well as in these observations, recorded under all sorts of conditions and relations and their behaviour correspondingly described, etc. They occurred, so it was testified, spontaneously as well as experimentally. Furthermore these images had been already described in two preceding observations. Specifically, the statements of the script in this observation were as follows:

"The thought" arises subconsciously first, "then the pictures [images] are completely formed" and "all is visualized" subconsciously. "I visualize," the script states, "subconsciously the scene I am writing about just as I do consciously." [The significance of this sentence is that the subject visualized subconsciously one scene while consciously during the experiment the content of her thought was of a different order (the scene of the room, the experimenter, etc.). Hence the eruption of the former was an hallucination.] The images "are in the subconscious mind while writing and then they are shifted into the conscious until they become visions." "When set, so to speak, they are reflected into the conscious mind." "It takes some time [a few seconds] for them to come into the conscious mind."

\section{(Observation II: The Spanish Fantasy.)}

A source of confusion and error in drawing conclusions lies in the fact that sometimes the script is written by a subconscious system (e.g. Juliana) differentiated from that from which the images are derived. Speaking figuratively there may be two or more 'layers' or 'strata' of subconscious systems underlying one another. The system that does the writing may then derive its images and thoughts from a deeper and 
more comprehensive underlying layer or system out of which the writing system has become crystallized as a differentiated system. In such a case the images emerge into this differentiated system from the deeper system and therefore the former does not know their origin but simply describes their content or the thoughts which they picture and which accompany them. Where all comes from it does not know. This is analogous to conscious imagery and thought. I have observed many examples of this kind of phenomenon. The consequence is that when the special script-producing system is interrogated the replies are inadequate and indefinite for lack of precise knowledge. Unless this is borne in mind confusion may result. This was the case in Observation No. II. Practically all the precise information that could be given was that the "visions" originated in "a deeper source of thought" and first appeared subconsciously to the writing system. Then, secondly, the writing of the ideas represented by the images caused the images to emerge into consciousness as hallucinations. But however this may have been the essential point is that the images first appeared subconsciously and then erupted into consciousness as the hallucination.

This observation was the first made and only a preliminary one to determine whether any positive results were likely to be obtained, and, if so, what was the best method of experimentation. Hence it was rather superficial. The chief points brought out by the subconscious analysis were:

"The 'pictures' seem to form from what has been written but the personal consciousness is not aware of it."

"The visions originate in the deeper source of thought and then the writing of them causes the visions to conjure up in the mind of the consciousness that is describing [orally] the visions"; i.e. the "personal consciousness."

"The deeper source of thought, which writes, has while writing the ideas contained in the pictures; so much so that that is where the mystery lies."

I am impelled here to insist again, as I have frequently done, that there is no the subconscious or the unconscious. In the structure of the mind there are greater and lesser systems of potential and dynamic processes which may be motivated by the urge of one or more 'dispositions.' These systems play and interplay with one another; and any one or more without entering the awareness of the personal attention may function 'subconsciously.' 'The concept of an unconscious, of which we read much nowadays, limiled to primitive instinctive processes, is 
based on inadequate knowledge of subconscious phenomena and is therefore scientifically amateurish. Such concepts belong to philosophy and are bound to go the way of all systems of philosophy after having served their usefulness, even as do scientific theories based on incomplete knowledge.

\section{(Observation III : The Treasure Chest.)}

The pictures (images) were first formed in the part of the mind that was answering the questionnaire; "the part that wrote the lines had the pictures and they became visible to the one sitting at your side [the subject]." The process was claimed to be as follows: The thoughts expressed in the versification came subconsciously on the way to keep her appointment. These thoughts were put into verse later, only, during the experiment and while writing, but the images were there before the composition was arranged and the "poetry came from the images.". "The thoughts were there first; then when they were grouped together to form the poetry the visions appeared [to the consciousness of the subject] during the process of the writing"; i.e. while writing the script the images erupted into consciousness as the hallucinations. "It took a few seconds for the images to become realistic to the conscious mind."

The order was:

1. Subconscious thoughts.

2. Subconscious images.

3. Subconscious verse.

4. Emergence of the images as hallucinations.

As to why the visions had more details than were described in the script, it was explained that there were subconscious thoughts of all the details of the fountain, but "you cannot write all the details as a vision can be described." In other observations substantially the same explanation was given. Thus, in Observation VI it was stated that "there is a subconscious process that can create visions quicker than the process of writing." This is emphasized by the fact that some visions are "mostly a memory," as was stated to be the case in one of the ballucinations of that observation. Then again (Observation IV) some hallucinations are recurrences or repetitions of subconsciously visualized scenes which have

1 The whole process was quite complex, according to the explanation given. Although the thoughts and images of the verse were in the subconscious system that wrote the script of this observation (III), they did not originate there but in a 'deeper' and more comprehensive subconscious system which was answering the questionnaire. From this 'stratum' they invadod the system that was the author of the seript and then the images erupted into consciousness as the hallucinations. This was the same order of affairs as occurred in the preceding observation (II). This same phenomenon, in kind, I had observed under other circumstances and in different forms. 
been already constructed subconsciously in all their details and are later revived and flashed as a whole before the mind.

As to what suggested, i.e. motivated the thoughts of the verse, it was explained, "I am not self-centred but I do know I have a certain amount of talent, and I suppose it was because that thought or thoughts were uppermost in my mind."

\section{(Observation IV: A Memory of Illness.)}

In reply to the question, "What work was being done subconsciously during the hallucinations from which the drawings were made?" the script asserted:

"The subconscious mind of both Susie and Juliana was at work projecting into the conscious mind the visions of Juliana and the palace, and a great desire to have reproduced the vision in the deepest part of the mind [so that it could be drawn]. Yes, there were images that formed the people-all things were images." "The subconscious mind thought it all out, it creates the images; then constant thought pushes them into the conscious mind."

\section{B. Artificially Induced Visual Hallucinations.}

A series of observations were now carried out of a character converse to the preceding. Instead of producing primarily subconscious script with secondarily resulting correlated images (hallucinations), artificial hallucinations were experimentally produced and the script employed to describe what if any subconscious 'thoughts' occurred during the hallucinations. The method employed was that of fixing the attention by means of a crystal. No directions were given as to what would be seen in the crystal. That was left to chance.

Observation VI. This series of three hallucinations is particularly instructive in that it shows the subconscious connection between hallucinations which apparently, as in dreams, have no obvious continuity by themselves. In the thoughts subconsciously written the connection is clearly shown especially in A and B of Hallucination 2, which I have consequently grouped together as one. The vision of her mother in a distant city suddenly without time interval shifts to a scene in Boston. The script enables the meaning of the shift to be understood. Subconsciously as the script explains, she wishes she could go home and see her mother once more sitting in the chair as she had often seen her and then after she has fulfilled this filial wish and obligation return to Boston 
and complete her vocal training for the stage. This connected subconscious thought fills in the gap between the hallucinations $A$ and $B$ and explains their meaning.

Likewise there is a connection between all three hallucinations, although less explicit, and notwithstanding they were separate, interrupted observations, but made within a few minutes of each other. She has an aspiration to go upon the stage in opera and act a certain part, that of a Spanish girl in a scenario which she has thought out (Hallucination 1). To accomplish this it will be necessary to remain East and not only support herself by working but at the same time fit herself by study. But she also longs to see her mother (Hallucination 2). This conflict she has often mentioned. Her solution is, as she also has frequently stated, to return home temporarily and then return to the East. But she has expressed doubts if she would be allowed to return if she should go home. Her wished for solution is contained in A and B. In $B$ the images are of herself singing by the side of her teacher, just such images as we should expect would be contained in the thought, though the hallucination is not a memory of a particular experience but a fabrication of an imagined general experience.

But to carry out her aspirations she needs a better paying position for temporary gain, so she applied for the position of assistant buyer and was called before the judges of the applicants. Hallucination 3 is a memory of that event.

\section{Three Subconsciously Connected Hallucinations.}

Halludination 1

I see a theatre stage. I see a little bit of a body (myself) on this great big stage and I am dressed like a Spanish girl and I have my arms up gesticulating as if singing. I seem to be gay. I am dressed with a shawl and fringe.

\section{Hallugination 2}

(A) I seo my mother sitting in a chair and myself leaning over her kissing her.

\section{[Shift]}

(B) I am in a studio by a grand piano. The teacher is playing and $I$ am standing by his side singing. I never saw the studio bofore. It is prettily furnished.

$$
\text { [Shift] }
$$

\section{Hallucination 3}

I see an office down at the store and I can see the three men I talked to about the position of assistant buyer: there are three chairs, a desk and myself. (I do not see the rest of the visionnot a complete picture like those I have seen.)
Script

I am thinking I would love to make my appearance on the stage as a singer and impersonate Juliana as a Spanish girl.

\section{ScRIPT}

(A) I wish I could seo $m y$ mother sitting in her chair and then come back East and

(B) Go on with my vocal work.

\section{SCRIPT}

I am thinking of the day I was called to the office of the judges to select an assistant buyer to train for the position. 
Following this observation the writing system was catechised and asked to explain why the hallucination of the studio showed more details than were contained in the automatic writing. The explanation given was that the content of hallucinations was often thought out subconsciously, first in detail before they were described, and that "there is a subconscious process that can create visions quicker than the process of writing." The vision of her mother was mostly a memory.

Observation VII. The next observation is extremely important in that, on the one hand, it illustrates the principle that script may be produced by more than one subconscious system, and, on the other, it shows a source of error that must be guarded against in such experiments. Otherwise we may be led astray by a failure to find a correlation between the hallucination and the script. In other words a hallucination may emerge from or be determined by another system than that which is writing. Furthermore it compels the conclusion that more than one subconscious system may actually function at one and the same time, and in this case three such systems. That script may be obtained from several distinct, different systems is well known, as is attested by the script obtained by mediums in claimed spiritistic communications. Of course psychological investigations have determined the same principle and the facts (e.g. Flournoy's classical observations in the case of Hélène Smith ${ }^{1}$. I need not mention numerous observations of my own illustrative of this point.) It may therefore be that the script obtained during a hallucination may show no correlation with the latter. In that case it may be that script can be obtained from another subconscious system which will contain very intimate correlations. This proved to be the case in this observation where the unrelated script first obtained was written by the 'Juliana system.' The hallucination consisted of a number of differing and shifting scenes. As the subject saw these scenes she sometimes laughed or commented on them. With this preamble I will now give the record of the observations, giving the hallucination and the corresponding seript of the 'Juliana system' first.

\section{Hallucination of the Fulfilment of an Aspiration.}

Scenes: 1. Funeral (laughs)-2. Church-3. Cemetery (laughs)4. New York-5. Theatre-6. Big buildings like an apartment house. (Given verbally and synchronously with the script of the 'Juliana system.')

$$
1 \text { "From India to the Planet Mars." }
$$




\section{Study of the Mechanism of Hallucinations}

Each scene shifted to the next one, as in a movie, without an apparent time interval. The subject experienced the successive scenes of the hallucination while the script was being written by the 'Juliana system' and described each verbally in general terms, such as: "I see a funeral""Now I see a church"- "It has changed to a cemetery," etc. The six scenes were accordingly recorded as above. Immediately after the hallucination was completed and nothing further appeared, each scene was taken in its order and the subject while the memory was vivid described the details as given below.

\section{HaLLUCination \\ Dotails of scenes given from memory immediately aftor their completion}

1. I saw a funeral-a caskct on a cart such as is used for soldiers with black drapery over it and a white cross of lilies on the top. I could see the petals. There wore black robed pricsts carrying huge white candles and somo little boys dressed in white following the casket and shaking incense burners-Streets paved with large rough cobble stones. "It seems to be in Italy-seoms foreign to me."] "I had a fecling at tho time the funeral was Juliana's. That is what made me laugh."]

2. Door of cathedral. I could see the tower and on top of it.a cross. The funeral procession was ontering the door. First tho priests, then tho casket and finally the little boys.

3. Barren landscape. A cemelery-graves far apart--ono grave opened and they were putting the casket in it. The pricsts and the boys wero standing around the grave, the boys waving the incense. There was no one else there at the funeral. ["That is the funny thing about it -there were no friends."]

4. I saw myself in New York just as I am now and I was walking down the street - high buildings on either side--there were busses, automobiles and pople ["I did not recognize the street."]

5. Theatre-I was going into it by the main streot door. I went down the side aisle to the drossing room and $I$ then saw myself on the stage dressed in Grecian white robo- 1 was simply standing there [" not acting-I did not know what I was going to do"] no other actors on the stageaudienoe in their seats.

6. Apartment house-I went in--took elevator -went to an apartment I felt to be mine-let mysolf in by latchkey. It was a beautifully furnished apartment, rugs, etc. I saw all tho furniture. I threw off a long neck piece of fur, then I stood at some long windows and looked out. I seemod con. siderably older than I am now, as if I were more of a woman than I am now-say 36-38 years.

\author{
SCRIPT \\ By the 'Juliana system' \\ written synchronously \\ with the hallucination \\ "I am at last out of this \\ world of toil, and with the \\ angels rest; my soul has wended \\ its way to the heavenly realms. \\ This is a real spirit message \\ [Signed] Juliana.
} now." 
The 'Juliana system' was now interrogated and it was easily demonstrated that this system had no causal relationship with the hallucination but that the spirit message was written as a jest.

[Here an interesting psychological phenomenon that $I$ have frequently observed and reported developed: namely, the emergence of emotional tones from a subconscious process. While this system was writing the spirit message and during the first part of the interrogation when the system manifested a humorous, almost hilarious, mood the subject was in high spirits, joyful, and felt the spirit of fun. Later, during the latter part of the interrogation when the 'Juliana system' admitted her tomfoolery and wrote of her past (the period when she was a double personality), the subject remarked without knowing what the hand wrote: "I feel serious, now. All my high spirits and feeling of fun have left me"; and then, as a coconscious confession of previous deception was written, "I have a sad, remorseful feeling ${ }^{1}$." This emergence of the feeling tones belonging to subconscious processes is of significance in the mechanism of moods and exalted and depressive states. The phenomenon accompanied some of the hallucinations.]

My first thought, in the failure to find in the Juliana script any psychological relationship of imagery with the hallucination, was that the findings would prove to be exceptional and that a different type of mechanism for the hallucination would be disclosed. On further investigation, however, this proved not to be the case, as a correlated script was obtained from another subconscious system-the 'Susie system.' This latter did not attempt to go into the details of the subconscious thoughts. I an rather sorry now I did not demand this, but my whole attention was concentrated upon the principle and the source of the first obtained seript and of the hallucination ${ }^{2}$.

When the subconscious 'Susie system' was tapped, as was now done, this system at once claimed to be the source of the hallucination and wrote the account given below of the 'thoughts' which went on subconsciously in this system while the hallucinations were being formed.

\footnotetext{
1 "I have a final confession to make-that I have told falsehoods und who can blame me. I was fooled for years by a lying subconseious mind who made me a puppet for its own trickery. Perhaps you will understand. Think of tho many years I was fooled into believing 1 was a soul." "This confession refers not to these experiments but to the carly period of double porsonality above mentioned, when the subconscious 'Juliana system" claimed to be the reincarnated soul of a Spanish peasant.

2 I'his involved considerable work, including rigid cross-examinations of the two systems that wrote. To reproduce here tho details of this oxamination would take us too far out of the way. It is sufficient to say that it transpired that the 'Juliana system" facetiously took control of the pencil and as a joke wrote the script pretending to be a spirit message. Although the message was short the 'Juliana system,' of course, might have gone on writing during the unfolding of the whole hallucination.
} 
I have arranged the 'thoughts' as given in a parallel column in apposition to the corresponding hallucination.

\section{HaLlucination}

Dotails of scenes given from momory immediately after their completion

1. I saw a funeral -a casket on a cart such as is used for soldiers with black drapory over it and a white cross of lilies on the top. I could see the petals. Thero wero black robed priests carrying huge white candles and some little boys dressed in white following the casket shaking incense burners. Streets paved with large rough cobble stones. ["It seems to be in Italy-seems foreign to me."] ["I had a feeling at the time the funeral was Juliana's. 'That is what made me laugh."]

2. Door of cathedral. I could see the tower and on top of it a cross. The funeral procession was entering the door. First the pricsts, then the casket and finally the littlo boys.

3. Barren landscapo. A cemelery-graves far apart-one grave opened and they were putting casket in it. The priests and tho boys were standing around the grave, the boys waving the incense. There was no one elso there at the funeral. ["'That is the funny thing about it-there were no friends." ]

4. I saw myself in New York just as I am now and I was walking down the street-high buildings on either side-there were busses, automobiles and people-["I did not recognize the street."]

5. Thealre-I was going into it by the main street door. I went down the side aisle to the dressing room and I then saw myself on the stage dressed in Grecian white robe-I was simply standing there ["not acting-I did not know what I was going to do"]-no other actors on the stageaudience in their seats.

6. Apartment house-I went in-took elevator-went to an apartmont I felt to be minolot myself in by latchkey. It was a beautifully furnished apartment, rugs, etc. I saw all the furniture. I threw off a long neck piece of fur, then $I$ stood at some long windows and looked out. I seemed considerably older than I am now, as if I was more of a woman than I am now-say 36-38 years.

The successive scenes of this hallucination are plainly the pictorial representation of a theme which is briefly set forth in the script of the 'Susie system.' This system, it should be explained, represents the aspirations of the normal self. The 'Juliana system' is a subconsciously
"I had thoughts of Juliana's Susic standing on her feet alone and gaining fame from her own conscious efforts and not loan. ing on any one for support." [Hero the 'Susie system' was told to be more explicit.]

"I had thoughts of a funeral of which I made the Juliana complex the central figure."

"And then I thought if the Susie complex would struggle she could gain fame as an actress"

"and maintain her own apartment just as she pleased, a long standing heart's desire." 
perseverating remnant of the former secondary and alternating personality from which this system has been derived.

Observation VIII. In this observation a series of shifting scenes developed. As each picture appeared the subject, as in Observation VII, called out the fact and described in general terms the scenes: "I see a street in New York"-_I see a scene in a theatre"-_A ship on the ocean," etc., with a few additional descriptive words. While these pictures were developing the hand automatically wrote the script signed 'Susie.' At the same time I recorded each picture and marked on the script the moment of its beginning and ending. As in the previous observation, immediately after the completion of the script and the hallucination, the subject described in detail from memory the pictures she had seen, taking them one at a time in the order of succession. This she was easily able to do as she could vividly revive them rich in detail. Each picture was then compared with those words of the script that were written during the occurrence of that picture. Arranging the pictures with the corresponding script in parallel columns I would invite your attention to the striking failure of correlation between the two synchronously occurring phenomena. Careful examination reveals that the hallucinations cannot be regarded as the emerging imagery of the subconscious process producing the script. For example: corresponding to the picture of a ship's dock (4), we have only the word "shall"; and to Hotel (6), the word "earth." The complete observation may be arranged as follows:

VIII. Hallucination in seven scenes: Visit to Italy.

Seenes: 1. Street in New York-2. Theatre-3. Ocean-4. Dock5. Subway-6. Hotel-7. Hotel Room.

(Described in general terms verbally and synchronously with the script of the 'Susie system.')

\section{SCRIPT OF The 'SUsie System.'}

"I am thinkinking [1] of New York and of the [2] fame I shall some day achieve as a great ac[3]tress and of my dreams of long standing shall [4] shall [5] hall mature and I shall travel to various sparts of [6] the earth [7] and I shall become overjoyous of my painstaking efforts and the fruit of my toil.

J. of Psych. (Med. Sect.) II

[Signed] Susie Sub[conscious]." 
[Note: Observe the halting and stammering at 3,4 and 5, and imperfect spelling. The script was crabbed and was written slowly and apparently with some difficulty. This corresponds with the theory that the images came from still another train of thought which inhibited this one.]

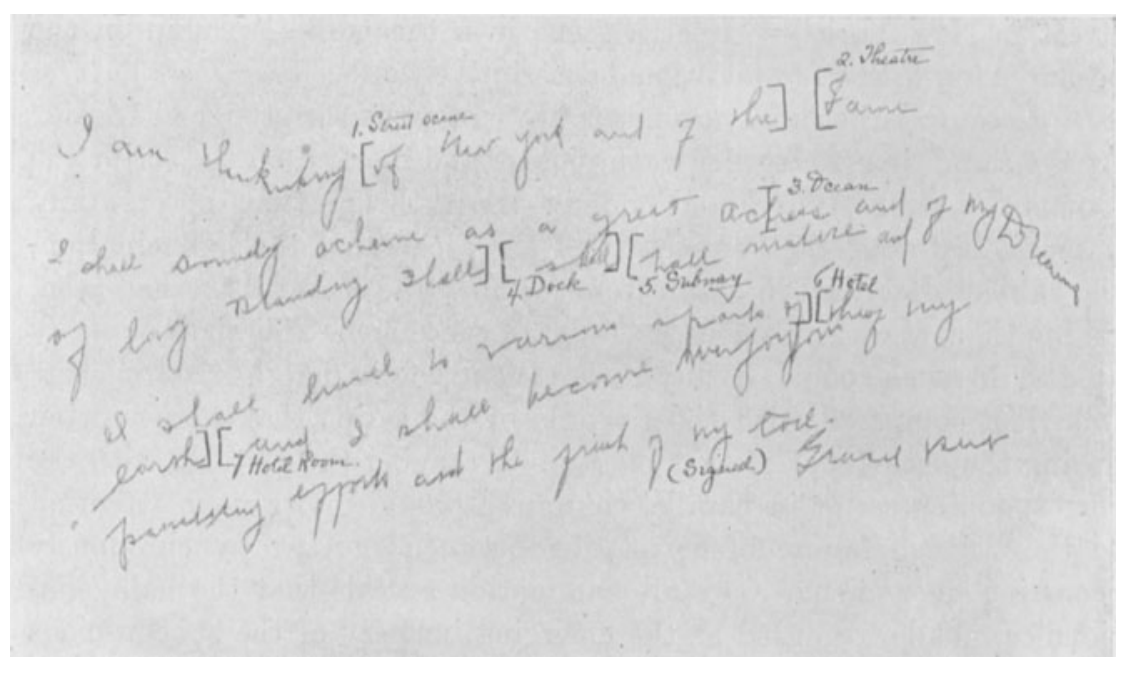

Fig. 3. Facsimile of Script in Olservation VIII.

\section{Hallucination}

Details given from memory immediately after production

1. Street scene in Now York.

I saw lots of peoplo-automobile busses-cabs -automobiles-mysolf-I seemed to be very intent and in a great hurry walking on the sidewalk.

2. Theatie.

I was in a theatre on the stage (not set-only a piuno and a man). I was boing taught by this man at the piano, singing. (I could not hear my voice.)

3. Ocean.

I was on a ship in midocean-no land in sight. 1 was walking on deck with the same man. It was dusk.

4. Dock.

I could see baggage being taken off by express and baggago people-lots of people hurrying around holloing for cabs-awful turmoil-I was with the man leaving the ship and on tho dockwas getting into a carriage with the man.

\section{SORIPT}

By the 'Susio system' written synchronously with the hallucination

I am thinkinking of New York and of the

fame I shull some day achicve as a great ac

tress and of my dreams of long standing shall

shall 
5. Subway.

'Trains in it. I went down tho subway from the carriage and got in the train-doors opened on the side as in London. It was in Italy because I saw funny language like Italian on the bill boards. No, it was Spanish language. I don't know where I was. It was Spanish or Italian. The strongest fecling in my mind was Italian.

6. Hotol.

Portecochère of a big white building. I wont in with this man, in a big lobby. I registered myselfI could see this man talking to the clerk, as if ho know him. It was as if he was tolling the elerk to look after mo. He tips his hat and goes away.

7. Hotel room.

A beautiful room-done in old rose draperies-. white furniture-imperial looking, it was so elegant. Difterent from anything you see in hotels. I was very tired. I was walking across the floor-all I could do and throw myself on the bed. I felt as if I said out loud-" At last I havo realized what I long hoped for." ["I don't know what that moant."

["I don't know who the man was-I folt that he was a foreigner-he knew how to sing-as if an impressario."]

Although no detailed correlation between the hallucination and the script can be postulated from the point of view of imagery of specific concrete thoughts, that is in the sense that the imagery of the hallucination can be recognized as the images of the specific ideas of the script, there was a general correspondence of the themes expressed by both. The script speaks in general terms of her aspirations and their fulfilment: the hallucinations as a whole represent a series of imaginary incidents which carry out concretely as fantasies these aspirations. But no concrete subconscious thoughts are discovered of which the hallucinations would be the normal images. The first two scenes (New York and Theatre) and the last (Hotel Room) might be interpreted as exceptions, but in a second script obtained later we shall see that the imagery precisely corresponds to images that would be expected of this second train of specific thoughts.

Undoubtedly the greneral theme of the first script was determined in accordance with a well known principle: that is to say, by the more specific ideas of a second subconscious process that induced the hallucinations.

In search of another system that might be responsible for the imagery of the hallucinations, the 'Juliana system' was now tapped by automatic writing. This system, after claiming that the pictures belonged to its 
thoughts, wrote successively, but of course from memory, the 'thoughts' that were subconsciously experienced during each hallucinatory scene. The given data may be tabulated as follows:

\section{Hallucination}

1. Street scone in New York.

I saw lots of people-automobile busses - cabs - automoliles - myselfI seemed to be very intent and in a great hurry walking on the sidewalk.

\section{Theatre.}

I was in a theatre on the stage-only a piano and man--(not set). I was being taught by this man at the piano, singing. (I could not hear my voice.)

\section{Oecan.}

I was on a ship in midocean-no land in sight. I was walking on deck with the same man. It was dusk.

\section{Dock.}

I could see baggage being taken off by express and buggage people-lots of pople hurrying around holloing for cabs -awful turmoil-I was with the man leaving the ship and on the dock-was getting into a carriage with the man.

5. Subway.

Trains in it. I went down the subway for the carriage and got in the traindoors opened on the side as in London. It was in Italy bocause I saw funny Ianguage like Italian on tho bill boards. No, it was Spanish language. I don't know what it was. It was Spanish or Italian. The strongest feeling in myself was Italian.

\section{Hotel.}

Porte-cochère of a big white building. I went in with this man, in a big lobby. I registered myself-I could see this man

\section{SCRIPT}

By 'Juliana system' written subsequent to the hallucination from memory. The form correspondingly

differs from synchronous script ${ }^{1}$.

- I thought I was in New York preparing my voice for an operatic career and 1 was on my way to the Motropolitan Opera House to see a man who would help me train my voice. That is why $I$ was in a hurry.

I was thinking that this noted manI do not know his name but he was there [Metropolitan Opera House] and was very much in carnest with my vocal progress; I was thinking I was rehearsing an opera with him that he claimed I would score a success in, and he proposed taking me to Italy to further my studies in that role.

I was thinking of the trip promised me at the theatro and of being on the liner bound for Italy where I. would resume my studies in the opera of Traviata; also that this man would take me there.

I was thinking that we had roached our destination and I was in Italy.

The scene as near as Susie told it was a perfect picture of what I was thinking.

I was thinking of passing through a subway. That was my thought-a European one.

1 As the seript purported to give the content of past thoughts by retrospection, the memories are given in rather general terms and it was obvionsly impossible to accurately corrolute in time with the "thoughts' the images within ench secne. Therefore I did not ask for minute details. The danger of artifucts in so doing is obvious.

I was thinking I was in Italy and I was very tired after the ocean voyage and vory joyous to be in the land of my dreams. 
talking to the elerk as if he knew him. It was as if he was telling the olork to look after me. He tips his hat and goes away.

\section{Hotel Room.}

A beutiful room--done in old rose draperies — white furniture - imperial looking, it was so elegant. Different from anything you see in hotels. I was very lired. I was walking across the floorall I could do and threw myself on the bed. I could foel as if I said out loud"at last I have realized what I long hoped for." ["I don't know what I meant."]

"I don't know who the man wasI felt he was a foreigner-he know how to sing-as if an improssario."]
[The script later claimed she was thinking of a hotel also, but forgot to write it. The fatigued condition followed this thought. It is significant of the absence of any intentional fubrieation of thoughts to fit the pietures that the seript here wont on as follows: "I was thinking this noted man was about to return to the hotel for mo and take mo to un opera houso to try my voice, and I was thinking the place was very durk and cold and outside it was very bright and sunny." While the peneil was writing this sentence the subject saw a vision of a theatre corresponding in details to the thought; but there were no such images in the original hallucination. When asked to explain this absence of hallucinatory imagery, the soript said it coukl not, but that the thought was "not vivid and did not develop into a pieture," as obviously is most generally the case: otherwise we all should be having hallucinations.]

I was thinking that my offorts in the future should bring me the reward of such a boutiful chamber and I thought out each detail of rose and ivory that Susic: deseribed ${ }^{1}$ only she did not tell all the wonderful things.

\section{Auditory Hallucinations.}

Alongside of the visual hallucinations it will have been noticed that there occurred auditory hallucinations in a number of instances (Observations I, II, III). Experiments were now undertaken to determine, if possible, whether or not the mechanism of such auditory phenomena was the same as that of the visual variety. First such evidence as might be derived from the self-analysis by the subconscious process which induced the hallucination was obtained. In evaluating this evidence it should be borne in mind that the particular auditory hallucinations to which the subconscious analysis referred were 'messages' from the subconscious to the personal consciousness, or a subconscious intention that

1 Referring to the conscious oral description of the hallucination by the subject. 
the words should be heard by the latter. This is not always a condition, as in Observations I and III. The subconscious, however, on numerous occasions has experienced this type of hallucination, as when, for instance, she acted as an amanuensis for the internal voice and to the dictation of the latter wrote a long story. Such messages were, however, quite common in this subject just as they are frequently met with in the hallucinations of the insane.

Observation $I X$. The subject heard an internal voice say:

(a) "Get that smoke out of your lungs"; and again,

(b) "Tell Dr Prince the Juliana complex is still holding her ideals1."

In response to a searching interrogation as to the mechanism of this and other auditory hallucinations the subconscious process gave testimony which may be summarized as follows:

In such hallucinations subconsciously the words are first intensively thought out and grouped together as auditory sounds or words; that as a result of this intense subconscious thinking the auditory words emerge into consciousness as the hallucination; but in addition, in order to produce such a hallucination, there is a subconscious 'striving' or 'aim' to have the thoughts emerge into awareness, a motive to have the thoughts heard; that if there was no such subconscious desire the subconscious thought would remain 'cut off' or 'away by itself' (i.e. dissociated and not in awareness).

In this way the script explains why sometimes with subconscious thoughts, as in automatic writing, auditory hallucinations occur, and sometimes not. Intenseness of thinking and striving were required although the two apparently were considered as identical. The script could not explain the phenomena further. The main point is that when the auditory hallucinations occurred, the words or auditory 'images' were first formed subconsciously and then, as the second step, emerged into awareness as the hallucination. It is obvious, however, that there must be another factor to cause the emergence, as auditory hallucinations do not invariably or even commonly accompany automatic writing, and they occur when no subconscious volition to this end is in evidence. Perhaps intensity or vividness of the 'images' may be sufficient and the

J In explanation of this the script wrote that it referred to a past conversation with me and the "high ideals" she "had heretofore set forth" in regard to smoking cigarettes which she conccived "harmful." The message apparently resulted from a subconscious memory of this conversation and the reflection: "I felt" (so the pencil wrote) "cigarettes were like morphine and I feel uneasy over them. I must not touch them." 
determining factor. Subconscious desire or volition was insisted upon by the script as the factor in the hallucinations in question which were plainly of the message type. Accordingly it was arranged, as a test of this claimed ability to produce a hallucination by subconscious volition, that the subconscious process was to write (without the knowledge of the personal consciousness, i.e. the subject), a sentence the words of which she would will the subject to hear as a hallucination, and the latter, if and when she heard an internal voice, was to speak aloud the words internally heard. The two-writing and internal voice-would then occur synchronously and could be recorded. The results were as follows:

Observation $X$. The hand wrote:

(a) "I am going to play Princess Theres on the stage"."

At the same moment while the hand was writing, without seeing the script and without knowledge ${ }^{2}$ of what was written, the subject exclaimed:

"I am going to play Princess Theres on the stage." These words she heard as an internal voice.

(b) (The hand wrote): "I smell cigarettes."

As before the subject heard a voice and exclaimed:

"I smell cigarettes."

In such observations we have written speech and verbal speech synchronously produced. The words of both were identical. The written words were produced by some process not in awareness without the knowledge of the subject. The subject pronounced the same words at the same time claiming that she heard them internally and her veracity is not open to doubt. That there must be a correlation is manifest and we must conclude that the same process that produced the script induced the internal voice. As this was done by prearranged intention it must have involved volition of some kind. (Of course I had no knowledge of what the words were to be.)

1 This was accompanied by a vision which as described was identically tho same as that experionced in Observation IV-the same court sceno, stage setting, murble floor, herself dancing, otc. When askod to explain how it was that the vision portrayed moro than was in the auditory hallucination and the acript, the hand wrote: "It had been pieturing for years [i.e. proviously constructed] and all that had to be done was to flash it beforo the conscious thought like a moving picture." 'This picture was "intensely thought of subconsciously." (Hore intensity rather than volition apparently was the determining factor.)

2 As she averred and I believe. 


\section{Drfam Imagery.}

The phenomena elicited in the following record and analysis of a dream, while not belonging strictly to hallucinations, yet are so closely allied and show such similar mechanisms that $I$ throw it in for good measure.

Observation XI. Dream of the Paprika Dance.

"I saw a stage with a huge red pepper in the centre of the stage and the lights were dim. Then I heard a loud burst of music and the scene changed and the large pepper opened in quarters and a large group of women in bright red tights were dancing around upon the quartered pepper. Upon their heads were caps of red, fashioned like the top of a red pepper with the stem serving as a tassel. The stage was now ablaze with light and just as I awakened it grew dim and the women scampered away."

After the narration of this dream, which impressed the dreamer because of its 'completeness,' the beauty of the music, and the vividness of the memory left of its details, the subject sketched the two dream scenes. These are here reproduced.

The method of automatic writing was then utilized to obtain subconscious memories as testimony of, first, what, if any, subconscious mental processes had gone on during the dream and therefore, of course, during sleep, and, second, the meaning of the dream and the motive for its production. In response to a rigid cross-examination the following was testified to by the script.

The idea of the dance had been subconsciously thought out the day before as a novelty for a vaudeville sketch. The motive was to create something "to put before a producer to gain an avenue of escape from the miserable shopwork." Every detail of the scenes was thought out including the music. There was also a desire to have the "conscious mind know of this creation." "In the day time the conscious mind was too busy to take in anything from the subconscious mind." But at night when "the mind was passive" this could be done. So when the mind was asleep "I thought and thought-very hard all I had created," the subconscious testified. All the details of the previously thought out scenes now "were grouped together into a finished product." "The intensity of my thoughts created the pictures, first in my complex of thoughts," and then these pictures or images entered "the conscious mind" as the dream. In other words, as with hallucinations, the normal 
Morton Prince
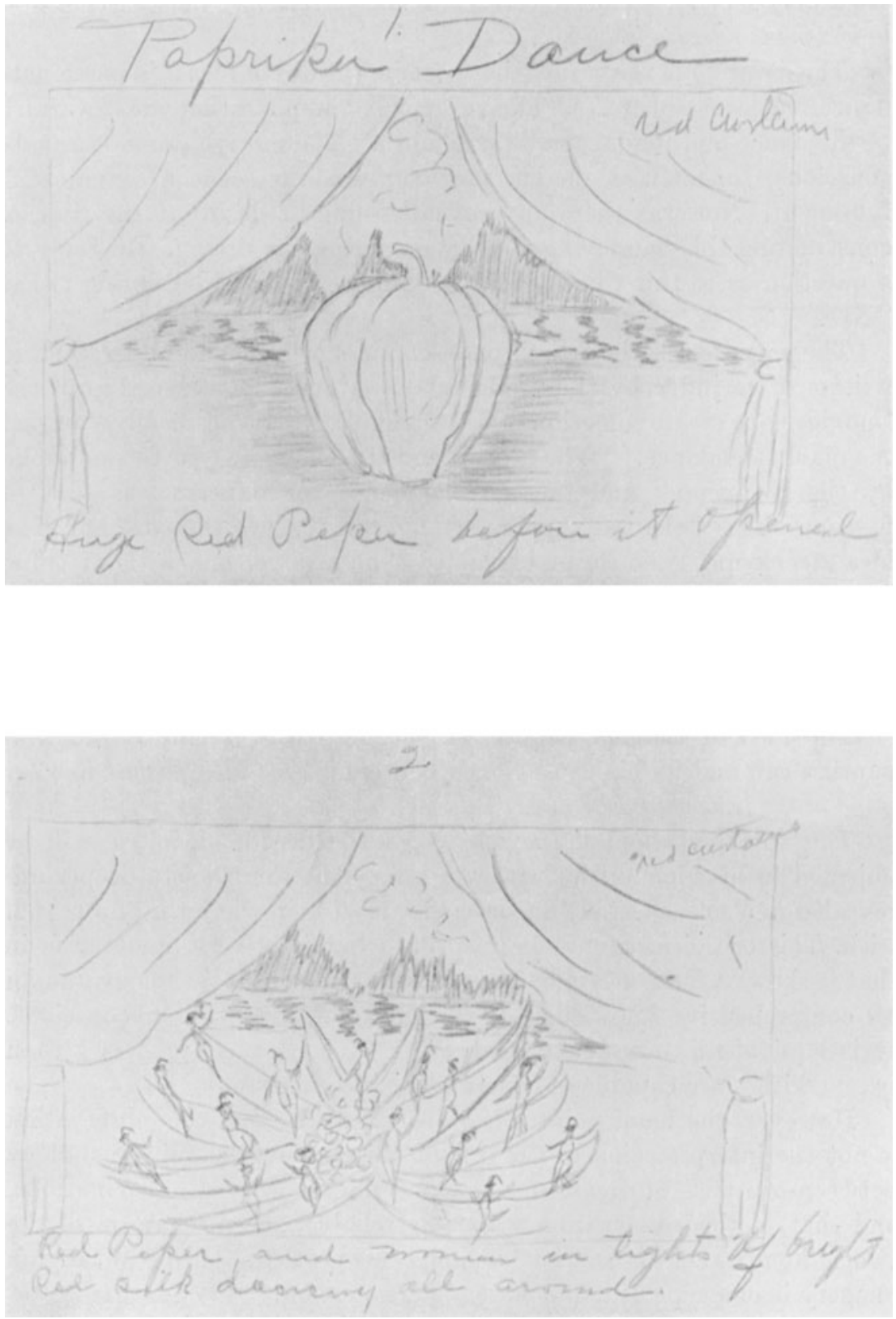

Fig. 4. Drawings of dronm imagery. 
imagery of thought, but now subconscious thought, emerged into consciousness to become the dream imagery ${ }^{1}$.

The meaning of the scene (that became the dream) was "a passionate dance and atmosphere." "The red pepper bespoke that idea, warmth of the dance and its dancers" [symbolism]. The motive was not a (subconscious) sexual wish on her part nor was the scene a sexual wish fulfilment. Nor was there any sexual feeling or desire at the time of constructing this vaudeville novelty or during the dream. (In reply to a question as to this the hand wrote emphatically, underscoring twice, "NO!")

The purpose was the artistic one-common we must admit to scenario writers if we judge by the present day agitation for censorship of the 'movies'- to create something that would draw and specifically "attract the male attendance." "The idea intended to be conveyed to the public by the red pepper and the movements of the dancers was that of passion." This "the red peppers symbolized because they are hot. The idea struck me," the script explained, "as a novel one without going into details and dissecting it as you are doing. I thought it a spicy, snappy idea. Now what would you think if you went and viewed it at a theatre?" "The women coming out of the pepper symbolized only beauty of form; nothing more."

The idea of the red pepper was suggested by seeing at home a paprika can and its highly seasoned contents. This idea flashed into her mind at the time as a good one.

This interpretation of the motive of the dream of course will be objected to by some critics who will insist that there was a deeper unrevealed and unsuspected 'unconscious' motive in the form of a sexual wish. This criticism cannot be disproved but it is very amateurish in that it shows a lack of familiarity with experimental psychology and an all comprehensive knowledge of the phenomena of the subconscious. It is equivalent to a denial that other 'unconscious' processes than sexual wishes are capable of constructive imagination.

However, the main point $I$ have in mind in citing this observation is not the interpretation of the dream but rather to show the analogy between one type of dream imagery and the imagery of hallucinations, and that, if this observation stands as reliable, the mechanism of the two is identical. This is what should be expected as, after all, dream imagery is one type of hallucinatory phenomenon.

1 Apparently this was not the expectation or intention but only a necessary consequence of the intensity of thought. The intention was to create a condition of bodily nervousness which, from previous experience, would result in the subject investigating the cause, etc. 


\section{Conclusions.}

1. There is a type of visual hallucination in which the imagery has its source in a dissociated mental process of which the subject is not consciously aware. Such a process is by definition a subconscious one.

2. The content of this subconscious process contains images identical with the normal imagery of conscious thought.

3. The hallucination is due to the emergence into consciousness of the previously subconscious images. This emergence necessarily results in a hallucination in that the imagery of the latter is not related to the content of the conscious train of thought but is foreign to the latter. This is a necessary consequence of the imagery being normal elements in a separate dissociated train (mental process).

4. The subconscious process is essentially a coconscious one of thought.

5. There is a type of auditory hallucination which has essentially the same mechanism.

6. As there is a type of hallucination (visual and auditory) occurring in the insanities which is identical in form, structure and behaviour with that produced experimentally in this study, the conclusion is justified that such hallucinations of the insane are due to the same mechanism.

7. The implication follows that when hallucinations of this type occur in the pathological psychoses, they are indications of the activity of a dissociated subconscious process as a factor in the psychosis.

8. The hallucinatory phenomenon carries the further implication that the genesis and psychopathology of the psychosis are to be found in the forces which have determined the dissociation and motivated the subconscious process.

9. It is not to be assumed that all hallucinations have the mechanism of the type here studied. It is possible that in those occurring in the intoxication psychoses and in certain forms of organic brain disease, particularly where the hallucination is of a simple unelaborated static structure, the imagery is induced by direct irritation of the cortical or subcortical neurones. It is difficult, however, to exclude the possibility that the intoxicating agent or organic process simply removes inhibition and permits subconscious dissociated processes to function. Nor can we find any analogy with the known effect of irritation of motor and other areas of the brain. Irritation, as observed, produces simple movements and simple sensory phenomena (noises). Still, the possibility of 
irritating factors becoming the immediate excitants of organized complexes of neurones underlying the hallucinations, cannot be excluded. This theory needs, however, to be proved. Even the irritative theory, as opposed to the psychogenetic theory, permits of the interpretation that the irritation excites a dissociated subconscious process from which images emerge into consciousness.

10. The psychological problem of differentiating between normal imagery and hallucination disappears in that they are identical, the hallucination being only the normal imagery of a dissociated subconscious process.

11. If the evidence given by subconscious introspection be not accepted, a possible interpretation of the hallucinatory imagery is that the images do not themselves occur primarily as subconscious elements, but by the same mechanism appear in awareness as the conscious correlates of a co-active dissociated physiological process. In other words, a subconscious process is neural, not psychical. On the other hand, such an interpretation does not take into account a large mass of collateral evidence for the psychical nature of processes occurring outside the field of awareness.

12. So far from a hallucination being a regression to an infantile form of thought (Freud), it is an element in highly developed adult thought processes.

13. The mechanism of the imagery of some dreams is the same as that of the hallucinations of the type here studied. 